\title{
Information infrastructure services for small and medium size manufacturers: The $\mathrm{MI}^{2} \mathrm{CI}$ project
}

\author{
J. Goossenaerts ${ }^{a}$, C.M. Acebedo ${ }^{b}$ \\ ${ }^{a}$ Eindhoven University of Technology, Information \& Technology \\ P.O.Box 513, Paviljoen, 5600 MB Eindhoven, The Netherlands \\ ${ }^{b}$ De La Salle University, Industrial Engineering Department \\ 2401 Taft Avenue, 1004 Manila, Philippines
}

\begin{abstract}
Advanced information and communication technologies have become major enablers of manufacturing industry operations and product and process development.

The paper proposes the concept of an information and command infrastructure and the role it can play as an enabler for lean, agile and sustainable industries in developing countries. An information infrastructure should provide an ongoing and lasting stream of information, decision and control services in support of the different life cycle phases of products and production resources, i.e. their design, production, use, distribution and disposal. Such services are particularly important for small and medium size manufacturers.

The $\mathrm{Ml}^{2} \mathrm{Cl}$ project deals with software technology for information and command infrastructures for industries. Its goals and current activities are described.
\end{abstract}

\section{Keywords}

Industrial development, information infrastructure, enterprise integration, small and medium size enterprises

\section{INTRODUCTION}

During the last decades the value added to raw materials through manufacturing has been increasing far more than the value of the raw materials, energy and agricultural goods 
traded on the world market. Because of this global market tendency developing countries feel a growing pressure to catch up in manufacturing technology. However, the growing variety of manufactured goods and the increasing expertise and know-how required for producing them, hamper these countries in achieving their industrial development goals, also in areas where small and midsized manufacturers play a substantial role. Meanwhile, the opinions are gaining acceptance that markets should be open and industrial production environmentally sustainable. By including these additional requirements in their industrial development agenda, many developing countries face an even larger catch-up hurdle: rather than starting from "simple" low-tech mass production, develop human resources, eliminate waste, improve skills, and increase product variety, developing countries are now expected to enter their industrial age at the levels of global competitiveness and environmental sustainability.

Having in view the development difficulties of emerging industries, meanwhile observing that manufacturing industry operations and product and process development are increasingly being executed by lean and agile enterprises and by extended and virtual enterprises, supported by advanced information and communication technology, UNU/IIST ${ }^{1}$ has initiated the $\mathrm{Ml}^{2} \mathrm{Cl}$ (Manufacturing Industry Information and Command Infrastructure) project. This project, which has been endorsed by UNIDO ${ }^{2}$, information and communications technologies based software applications that can support emerging manufacturing industries in developing countries.

This paper explains the background, goals, planned deliverables and progress of the $\mathrm{Ml}^{2} \mathrm{Cl}$ project. Section 2 gives a short characterization of the industrial development challenge. Section 3 describes the $\mathrm{MI}^{2} \mathrm{Cl}$ concept, it explains an architecture of an information and command infrastructure and the role that enterprise and artifact models play in the development and use of the infrastructure services. Model execution engines and innovation coaches are two important generic services. Section 4 discribes the current status of the $\mathrm{MI}^{2} \mathrm{Cl}$ project.

\section{THE INDUSTRIAL DEVELOPMENT CHALLENGE}

\section{The Development Target}

Advanced and future industries are characterized by their ability to produce a large variety of products in a lean, agile and sustainable way, and by doing this with consideration of the complete life cycles of the products and production means. For details on particular production management and engineering techniques one could check Womack et al. (1990) for an account on the development of lean production, Goldman et al. (1994) for a description of agile enterprises, and Alting and Jørgensen (1993) for techniques to achieve sustainable production and life cycle assessment.

Summarizing, and without paying attention to how to achieve these qualities, one can call an enterprise or industry lean when it is capable of achieving results without using superfluous resources (e.g., equipment, workers, investments, stock), it is called agile when it is capable of responding to change quickly and intelligently. An industry is sustainable

\footnotetext{
${ }^{1}$ UNU/IIST: United Nations University, International Institute of Software Technology (in Macau).
}

${ }^{2}$ UNIDO: United Nations Industrial Development Organisation (HQ in Vienna, Austria). 
when products are designed, produced, distributed and disposed with minimal (or none) environmental and occupational health damages, and with minimal use and disposal of resources (materials and energy) (Alting and Jørgensen, 1993).

\section{The Leverage of Infrastructure}

Emerging industries face several difficulties in rapidly moving from an early stage of development to a mode of production in which extended enterprises (Browne et al., 1995) and virtual enterprises (Goldman et al., 1994) show flexible responsiveness, also to needs of the local market, and achieve product variety, sophistication, optimal usage of capacity, and environmental sustainability. Difficulties are caused by plenty of factors, including the absence of a favourable business environment and physical infrastructure, the lack of human resources - in a wide range of specialized skills -, the scarcity of capital, and the lack of technology. This mix of difficulties can not be overcome by a single measure. The proposers of the $\mathrm{Ml}^{2} \mathrm{Cl}$ project expect a positive effect from the combination in an information and command infrastructure of consolidated ICT, insights regarding business process engineering (Hammer and Champy, 1993), and systematized knowledge about products and processes as captured in artifact and enterprise models. An information and command infrastructure may help to raise productivity and lower production costs, as do the traditional infrastructure networks, notably in the areas of sanitation, water, power, transportation, irrigation, roads and telecom. In addition it may leverage the innovation of products and processes and be an enabler for industrial development.

\section{Failures and Successes of Past IT Deployment}

In spite of the theoretical importance of information technologies "many developing countries are often suspicious of information technology as an agent of perpetual dependence upon industrialized countries, and feel threatened by informatization" (Yamakage, 1990). Also, for projects that have been implemented, the understanding of the impact of information on development has remained largely anecdotal, and evaluation of interventions has usually been related to short-term outputs (Stone, 1993).

The skepticism regarding the impact on (industrial) development of traditional information technology - i.e. "isolated" databases or software packages - may be justified: Information technology is usually provided by vendors for specific, detailed needs, and users acquire packages one-by-one. After some time, needs are encountered for exchanging data between packages, for example via underlying databases, and for functions of one package to invoke functions of another. Often such needs have been frustrated by the inability to link up such data and such functions, or by the error-proneness of such links. As a result several investments seem to miss their targets. Moreover, developing countries are often not in the position to meet the resulting perpetual demand for investments, without the return to earlier investments being proven.

Similar interfacing problems with the use of computers and software applications have appeared elsewhere. For instance in manufacturing (Van Houten, 1992). In the field of business systems the problems of interfacing between various function domains has nurtured the development of enterprise wide information systems - built around databases - which achieve an intra-enterprise information and command infrastructure functionality (Scheer, 1994). For manufacturing systems, and in various factories, in house solutions 
exist (Matsuda et al., 1993).

By considering the wider scope aspects of enterprise operations - as is done in CIMOSA (AMICE, 1993) and ARIS (Scheer, 1994)-, and also projects (innovations), market operations and extended-enterprise projects - as intended in the $\mathrm{Ml}^{2} \mathrm{Cl}$ project - one can specify and develop information and command infrastructures which provide information, decision and control support for full business processes within enterprises, extended enterprises and markets or industries as a whole.

\section{The Role of SMEs}

The production of large varieties of high-value products requires networks of enterprises, including many small and medium size manufacturers, to innovate and concert valueadding processes.

The important share which SMEs have in an economy stem from the variety of services and products which they supply, the low costs at which they operate, the relative ease with which they can innovate, and the number of jobs they create. Many countries have sought ways and means to stimulate and increase the numbers of small firms starting up. The possibilities for small businesses to link up to an information and command infrastructure have to be considered from the outset.

\section{$3 \quad \mathrm{Ml}^{2} \mathrm{Cl}$ : THE CONCEPT}

A manufacturing industry information and command infrastructure $\left(\mathrm{MI} \mathrm{I}^{2} \mathrm{Cl}\right)$ is a large and complex system without centralized control, which supports the cooperative behaviour of many agents (public bodies, enterprises and consumers) having their own independent interests, values and modes of operation. These agents should meet economic, social, sustainability and environmental challenges and therefore cooperate and compete, abiding by rules spelled out in the business environment.

A manufacturing industry information and command infrastructure can enable the development of virtual enterprises and joint product and process development by small and medium enterprises at much lower costs than at present. Tools for ERP (enterprise resource planning), CAD, CAM and CIM, and CALS services can be interfaced to the infrastructure, and new applications can be designed to draw on the infrastructure services. By positioning new applications or services in the infrastructure, they can be focussed, and impacts and enabling role for business and manufacturing processes can be assessed more accurately.

\subsection{The MiViPoRo Framework}

The MiViPoRo framework (short for: Modules for innovation, Versions for improvement, Proxies for operation, Records for observation) is proposed by the first author (1996) to guide the requirements definition and development of generic system services for an information infrastructure for manufacturing industry. The framework serves as a basis for unifiying information and command requirements of autonomous agents as they involve in enterprises and the life spans of artifacts. It offers guidance for organizing the future development of artifact life span oriented applications for manufacturing industries, and 
shows opportunities for sharing applications and information.

MiViPoRo divides the problem domain of manufacturing industry into two sub-domains and links the required generic services and primitive objects to four activity layers.

The sub-domains are: the physical domain comprising the physical space, time and matter, with artifacts, agents and cells (spatial units) having life cycles in it; and the $c y$ bernetic domain which adds communication and control services to the physical domain. In the latter domain each (physical) entity is represented by at most one proxy. The term interflow denotes the coordination and monitoring of time\&space\&matter situated physical processes by means of computational processes in the cybernetic domain. Interface channels exist between physical objects in the physical domain and proxies in the cybernetic domain.

The four activity layers span the two sub-domains and cover observations, operations, improvements and innovations (compare with the three layer model of Inagaki (1993) (operations, improvements and innovations)). In each of these layers, work - action in the physical domain - has to be connected to computations and communications in the cybernetic domain.

The MiViPoRo framework identifies the following generic services: innovation coaches, version managers, secure model execution engines, browsers and report generators, and user interfaces.

\section{Model Execution Engine}

A model execution engine is a software application that manages the use of (sections of ) enterprise models, enterprise data - including workflow data - , artifact modules and artifact data in interactions with one or more agents during their work (as part of a business process involving a number of artifacts - products and/or resources - ) - see also CEN Report 1832 (1995). Model execution engines support interfaces for all agents - employees at companies and public bodies, and consumers - involved in any of the life phases of an artifact type or occurrence, in reference to the modules of the artifact type.

The model execution services should ensure some general properties, such as: (a) access restrictions and security requirements are enforced during access to the system; (b) a minimal number of records is kept, for artifact types and occurrences such that the recollection of an artifact history or artifact model (global data sourcing) and the (global) propagation of changes is always easy (either in synchronous or asynchronous mode); (c) a wide range of functions are supported, that are typical for the agents dealing with artifact types or occurrences (e.g., producers, retailers, transporters, customs, consumers, market researchers, ...); (d) model execution engines must be capable of coordinating processes involving distributed agents.

\section{Innovation Coach}

An innovation coach is a software system that supports (business) engineers in: (a) designing (distributed) artifact possible life models and (virtual) enterprise models; (b) evaluating alternative designs with respect to criteria (performance, manufacturability, reliability, (life cycle) cost, safety, ...); (c) implementing (realizing) the production systems (often enterprise networks) that can source components, produce and distribute, maintain and dispose the artifacts. 
Innovation coaches support innovation layer activities. ICT applications can be developed which implement standard protocols for sharing information and for coordinating decisions and control in the innovation processes of extended and virtual enterprises.

\subsection{A Hypothetical Federation of ALPS}

An information and command infrastructure responds to the need for efficiency in business and operations for artifact life spans. As a product or resource progresses through its life it gets involved in several possible or required situations with users, owners, traders or other specialized agents. Each of these agents has skills or interests that are typical for the life phase of the product type or of its occurrences.

One possibility is to base the $\mathrm{Ml}^{2} \mathrm{Cl}$ services on a federation of Artifact Life Phase Service bodies (or ALPS) as illustrated below. ALPSs use the generic services of innovation coach and secure model execution engine in interactions with agents dealing with products and resources to offer specific services. The services which different ALPS offer, should be complementary. Taken together these services should extend over all possible life phases of a wide range of artifacts, such that for each possible or required phase in the life of any artifact and for the agents involved, there are ALPSs that can provide the relevant support, at any place, whenever it is needed. Typically, agents will operate within certain territories. The global connectivity that is offered by telecommunications technologies results in less restrictions for the ALPSs. A hypothetical federation of ALPSs could comprise the following:

Central Artifact Register (CAR): The CAR register is used for classifying (in a universal classification) and uniquely identifying artifact \& material types, naming (trademarks), coding, certifying, patenting all products, parts and goods that are produced, disposed or traded in a national or international territory. The CAR could also be used for keeping track of volumes or quantities imported, consumed, produced, exported, and disposed of or recycled.

Sectorial Artifact Data Warehouse (SADW): The SADW is used for keeping artifact life phase models and product histories that are typical for products as they occur in an industrial sector or market segment (e.g., there could be an SADW for cars, and another one for electronic components). A supplier should place its assortment in the warehouse and be responsible for its own information. Customers can indicate for which artifacts they want to receive updates. Users should be able to indicate who may or may not receive basic product information.

Proprietary Artifact Data Warehouse (PADW): The PADW is used by a producer, trader, recycler or disposer to store all data relevant for any of the product or resource life phases (production, transportation, use, maintenance, repair, dis-assembly, recycling, safe disposal) in which he is involved. The life phase models and artifact histories are to be stored and made accessable to authorized users, including public authorities (e.g., for safety and environmental certification), or anyone else who may get involved in the life span of the artifact type, or one of its occurrences.

Private Artifact History Records (PAHR): The owner of an occurrence of a artifact type (with a certain persistence, resource contents or value) is encouraged to maintain a artifact history describing all milestones in its life (e.g., upgradings, repairs, maintenance, sellings). This artifact history could be passed on with the artifact when it changes owner. 
In a country, the federation formed by one CAR, SADWs (e.g., one or more per industrial sector), PADWs (one or more per company), and PAHR's (one per consumer) forms an instrument for artifact life cycle and business operations and process engineering, entrepreneuring and (industrial) policy planning. It could support a wide range of functions that are typical for the various agents, artifact types and artifact occurrences as they meet in possible situations.

The federation of artifact life phase services can support the global sourcing of artifact model data (types) and process models (types), artifact histories (occurrences), and workflow elements (occurrences) in support of identification, decision and action, prior to the global propagation of the consequences of these actions. A federation of ALPSs can provide us with an infrastructure on which applications can be developed for improving the productivity of global sourcing and global distribution, for environment protection, reducing the use of energy and materials, and increasing recyclability and refurbishment.

\subsection{Meeting the Needs of SMEs}

SMEs are weak in acquiring know how, capital, technology and human resources. An information infrastructure, conceived as a federation of artifact life phase service bodies, can meet the needs of SME's in (at least) two ways:

(i) $\mathrm{MI}^{2} \mathrm{Cl}$ facilitates the communications of an SME with its business partners: The role which an SME plays in a production process, usually concerns a specialized manufacturing process for one or a few life phases of parts. In order to deploy its capabilities - the core competences - for a range of products, the SME has to involve in business processes with a number of other market-players. The number of partners may grow with the number of end-products to which the SME contributes. Communications also increase when production becomes customer-order driven (Browne et al., 1995). For the SME it is vital that it can focus on core competences and that it can rely on standardized and secure information infrastructure services in support of its communications. The infrastructure services should extend over operations, improvements and business and engineering innovations (contract acquisition, product and process innovations, quality assurance).

(ii) $\mathrm{MI}^{2} \mathrm{Cl}$ supports the easy incorporation of changes in the business environment into the SME's processes. The business processes of SMEs are to a large extent influenced by the environment in which they are active. Likewise many commonalities between (partial) enterprise models for SME will have their origin in the market rules (the confluence between enterprise operations and market behavioural rules). For the SME it will be important that changes in the rules and conditions of the business environment get automatically, or with minimal burden, reflected in its business processes.

\section{THE $\mathrm{MI}^{2} \mathrm{Cl}$ PROJECT}

\subsection{Expected Deliverables}

The value added services that a global network can offer to manufacturing industry depend on a standardized and systematized representation of the data on products, processes and manufacturing technology. Standards in enterprise modelling (ENV 40003 (Cen/Cenelec, 
1990) and ENV 12204 (Cen, 1995) ) and product data technology (STEP) (Gielingh, 1993) are very relevant to achieve this. Also the GNOSIS project (Toyama, 1996) of the IMS Program (Intelligent Manufacturing Systems). (IMS, 1994) focusses on knowledge systematization.

The $\mathrm{Ml}^{2} \mathrm{Cl}$ project aims to accelerate the introduction of information and command infrastructures for industries in developing countries. The project proposes radically new opportunities for synergies involving industrial policy planners working at the global and national levels, entrepreneurs and engineers working at the company level, and consumers. It identifies objectives and technical deliverables (enterprise, product and process models, services) for three levels of cooperation (multi-lateral, national, and among companies and consumers) and two levels of competition (among countries and among companies) in industrial development.

Global, International (Multi-lateral) . A multi-lateral information infrastructure would include: (i) Possible lives models of artifacts, processes, plants, enterprises, market and industry which have a general value and are no longer competitive. These modules would typically be installed at CAR and at SADWs and be expressed in the prevailing international standards. (ii) Techniques, standards, and software tools for constructing and implementing new modules which are compatible with those at the CAR and SADWs (the constructed modules would incorporate product properties on which companies wish to compete in the market). (iii) The definition of a basic federation of ALPSs which should enable a country in sustaining a basic industry and infrastructure (including companies and public bodies for roads and transportations, telecom, energy, water, waste disposal, agriculture and food industry, health services, repair shops ...).

National (country-wide) : (iv) Using the techniques, standards, and software tools for constructing and implementing new modules provided at the global level, a country or region can define modules which it sees fit to its industrial development, and implement them at particular SADWs, PADWs, and PAHRs. These modules and ALPSs would be seen as extensions to those offered at the multi-lateral level.

A country-wide infrastructure, embedded in a multi-lateral infrastructure, can clearly play a role in a competition between countries. Access rights should be handled within the constraints that are agreed at the multi-lateral level.

A country-wide manufacturing industry information and command infrastructure, comprising dedicated life cycle service bodies, would support market operations and entrepreneurial projects. It would also be an instrument for education and human resource development.

Local, for companies and consumers : $(v)$ The multi-lateral infrastructure, extended with the national information infrastructure, forms a context where companies can compete on core-competences in producing artifacts and providing services. At this level the PADWs of companies and the PAHRs of consumers are introduced. They play a role in the competition between companies, again within the constraints consolidated in multi-lateral and national infrastructure services. 
The company information systems - typically designed or developed in (computer aided) entrepreneurial or engineering projects - would support the operations of the company and its interfaces to the market and industry. Its embedding in the national and multi-lateral infrastructure ensures a maximal reuse of available services and minimal overheads when responding to change in the business environment.

Software tools and the modelling framework could support the carrying out of entrepreneurial feasibility studies (as described for instance by Behrens and Hawranek (1991), in a manner which draws on concurrent engineering (see for instance Sohlenius, 1992), and the modelling approaches supporting it (Kimura, 1993).

An exploitation strategy for the multi-lateral and national information infrastructure systems should draw on a detailed study of infrastructure economics, and relevant findings from public utilities, transportation and especially telecommunications infrastructure.

\subsection{Current Activities: Technology Development}

The achievement of the long-term goals and deliverables of the $\mathrm{Ml}^{2} \mathrm{Cl}$ project is pursued along different lines. Progress on the formation of a partnership to develop and demonstrate the $\mathrm{MI}^{2} \mathrm{Cl}$ functionality has been slow. At present most emphasis is on technology consolidation and development.

\section{Enterprise and Industry Modelling}

The mathematical modeling of enterprises (in all aspects of marketing, administration, finance and especially development and production), supply-chains and products, is a prerequisite for the systematic development of the model execution engines and innovation coaches which will animate the information and command infrastructure.

As regards the problem domain modelling, the project draws on the use of enterprise models and reference models as tools for organizing and integrating information about enterprise processes. This area has been well established. See for instance ENV 40 003(1990) , Scheer (1994), AMICE (1993), Spur et al. (1994). Goossenaerts \& Bjørner (1994) introduce also the concept of industry model.

\section{Model Execution Engines}

At present researchers at UNU/IIST are studying the applicability of the emerging ODP (Open Distributed Processing) Reference Model as the underlying computational structure for agile manufacturing in an information infrastructure environment. Based on the formal model and using the underlying computational structure, one is approaching an implementation of the prototype model execution engine for education and training computerised business game simulating decision-making in real-life manufacturing.

Towards this goal the usual UNU/IIST methodology is followed. The prototype development proceeds in four stages:

(i) Broad (informal) study of the issues in manufacturing industry, as they appear in the intra-enterprise, inter-enterprise and inter-market contexts. The emphasis is on decisionmaking within marketing, administration, finance and production activities.

(ii) Formalization of the structure and operations of a manufacturing enterprise in RSL (RAISE, 1992), and how different enterprises interact in the network of suppliers. This 
will take marketing, finance and production aspects into account and ultimately provide requirements for simulation software - the business game.

(iii) Refinement of the model above, showing how simulation software can be implemented on the ODP computational platform. We shall demonstrate refinement to preserve essential properties of the model.

(iv) Construction, first using tools to translate RSL specifications into C, of the prototype simulation software, and using Athena libraries for windowing and graphics, and CORBA (OMG, 1991) for ODP.

As of May 1996, the $\mathrm{Ml}^{2} \mathrm{Cl}$ project has accomplished a portion of each of the four stages. A domain analysis has been conducted on the intra-enterprise level with heavy focus on production. The domain can be expanded in two directions: vertical and horizontal extensions. The vertical extensions will deal with inter- enterprise and inter-market abstraction levels. Inter- enterprise analysis will highlight the market and the trade that goes on between enterprise in the supply chain. Inter-market will focus on the interactions between markets and the general support relations across all goods. The horizontal extension will deal with deeper analysis of the four aspects of a manufacturing enterprise. Existing mathematical and qualitative techniques and tools are to be taken into account in modelling the generic model. The RSL model of the manufacturing enterprise will follow this further development.

A business game was also developed which captures aspects of a manufacturing enterprise in a gaming environment. The game is formalized through an RSL model and later converted into a simulation software. The software uses $\mathrm{C}$ and Athena which allows the game to be played on a local area network.

\section{SUMMARY AND FUTURE CHALLENGES}

The industrial development challenge and the enabling role which information and command infrastructure may play in meeting this challenge have been sketched. SME in particular should seize the opportunities which are offered by new generic computer networking technologies. To this end a systematization (into modular models) of knowledge about business and manufacturing processes and product life cycles is required, and model execution engines and innovation coaches must be developed. The latter should be capable of dynamically binding distributed model components and occurrences in support of decision making and distributed workflow management.

This paper has explored the problem domain of advanced manufacturing and considered the difficult situation of SMEs as players in this domain. An architecture of an information and command infrastructure for manufacturing industry, and the services of model execution engines and innovation coaches, have been described.

The $\mathrm{Ml}^{2} \mathrm{Cl}$ project has been proposed through its goals and current activities. Major challenges for the future are: the demonstration of distributed artifact and process models, the development of secure model execution engines to animate them; the prototype development of an innovation coach; and the identification of a partnership which can develop and demonstrate the $\mathrm{Ml}^{2} \mathrm{Cl}$ infrastructure services. 


\section{REFERENCES}

Alting, L. and Jørgensen, J. (1993) The Life cycle concept as a basis for sustainable industrial production. Annals of the CIRP, 42/1.

Behrens, W., and Hawranek, P.M. (1991) Manual for the Preparation of Industrial Feasibility Studies. UNIDO, Vienna.

Browne, J., Sackett, P. J., and Wortmann, J.C. (1995). Future manufacturing systems towards the extended enterprise. In: Computers in Industry, Vol. 25:235-254.

CEN/CENELEC (1990) ENV 40 003: Computer integrated manufacturing - systems architecture - framework for enterprise modelling. European prestandard, CEN/CENELEC, Rue de Stassart 36, 1050 Brussels, Belgium.

CEN Report 1832 (1995) CIM systems architecture - enterprise model execution and integration services - statement of requirements. CEN/CENELEC, Rue de Stassart 36, 1050 Brussels, Belgium.

CEN (1995) ENV 12204 Advanced Manufacturing Technology - Systems Architecture Constructs for Enterprise Modelling. European prestandard, CEN, Brussels.

ESPRIT Consortium AMICE, editor. (1993) CIMOSA: Open System Architecture for CIM. Springer Verlag, Berlin, 2nd, rev. and ext. edition.

Gielingh, W. (1993) Towards an infrastructure for product data technology. In Realizing CIM's Industrial Potential, pages 70-81. IOS Press, Amsterdam.

Goldman, S.L., Nagel, R.N. and Preis, K. (1994) Agile Competitors and Virtual Organizations. Van Nostrand Reinhold, New York, NY.

Goossenaerts, J. (1996) A Framework for Connecting Work and Information Infrastructure. This volume.

Goossenaerts, J. and Bjørner, D. (1994) Generic models for manufacturing industry. Technical report no. 32, UNU/IIST, P.O.Box 3058, Macau, December 1994. as: $\mathrm{MI}^{2} \mathrm{Cl}$ Reference Handbook Ch. IV.1.

Goossenaerts, J. and Bjørner, D. (1994) Interflow systems for manufacturing: Concepts and a construction. In: Ladet, P. and Vernadat, F.B. editors, Integrated Manufacturing Systems Engineering - Proceedings of the European Workshop on Integrated Manufacturing Systems Engineering (IMSE'94). , Chapman \& Hall, London, UK.

Hammer, M., and Champy, J. (1993) Reengineering the Corporation. Harper Collins Publishers, Inc., New York.

van Houten, F.J.A.M. (1992) Manufacturing interfaces. Annals of the CIRP, 41/2.

IMS (Intelligent Manufacturing Systems) - A Program for International Cooperation in Advanced Manufacturing / final report of the international steering committee adopted at ISC6, Hawaii, 24 to 26 January, 1994. Report, IMS Consortium.

Inagaki, K. (1993) The role of information systems infrastructure in production management. In: Yoshikawa. H. and Goossenaerts, J., editors, Information Infrastructure Systems for Manufacturing, IFIP Transactions B-14. Elsevier Science B.V. (North Holland), Amsterdam. 
Kimura, F. (1993) A computer-supported framework for concurrent engineering - an approach based on virtual manufacturing. In: Yoshikawa, H., and Goossenaerts, J., editors, Information Infrastructure Systems for Manufacturing, IFIP Transactions B-14. Elsevier Science B.V. (North Holland), Amsterdam.

Matsuda, M., Wakai, H., and Fukuzawa, M. (1993) Software requirements for a cell-based information environment in manufacturing: Present and future. In Proceedings of the Symposium on Manufacturing Application Programming Language Environments, Ottawa, Ontario, Canada, October 4-5 1993. National Research Council of Canada.

Object Management Group (1991) The Common Object Request Broker: Architecture and Specification. John Wiley \& Sons, Inc., New York. OMG Document Number 91.12.1.

The RAISE Language Group (1992) The RAISE Specification Language. Prentice Hall, New York.

Scheer, A.-W. (1994) Business Process Engineering - Reference Models for Industrial Enterprises. Springer Verlag, Berlin.

Sohlenius, G. (1992) Concurrent engineering. Annals of the CIRP, 41/2.

Spur, G., Mertins, K., and Jochem, R. (1994) Integrated Enterprise Modelling. Beuth Verlag GmbH, D-10772 Berlin.

Stone, M.B. (1993) Foreword. In M.J. Menou, editor, Measuring The Impact of Information on Development. International Development Research Center, Ottawa, Canada.

Toyama, M. (1996) GNOSIS: Knowledge systematization; configuration systems for design and manufacturing. In this volume.

Womack, J.P., Jones, D.T. and Roos, D. (1990) The Machine that Changed the World. MIT Rawson Associates.

Yamakage, S. (1990) A strategy for IT-led development: Impact of information technology on development policies. In T. Saito, editor, Information Technology-led Development. Asian Productivity Organization, Tokyo. 